\title{
Ways to Regulation of the Quantity of Potato Moths and Algorithms for Diagnosing its Development
}

Sitora Karimova

Department of Biotechnology, Turkey.

Corresponding Author: Sitora Karimova, Department of Biotechnology, Turkey.

Received date: April 01, 2021; Accepted date: July 13, 2021; Published date: August 13, 2021

Citation: Karimova S., (2021) Ways to Regulation of the Quantity of Potato Moths and Algorithms for Diagnosing its Development. J, Biotechnology and Bioprocessing 2(6); DOI: 10.31579/2766-2314/036

Copyright: ( ) 2021, sitora karimova, This is an open access article distributed under the Creative Commons Attribution License, which permits unrestricted use, distribution, and reproduction in any medium, provided the original work is properly cited.

\begin{abstract}
Consideration of issues of the quantity of potato moths according to the data of pheromone traps, which make it possible to simplify the monitoring system for the development of the pest and make optimal decisions in their extermination.

We have considered the regulation of the number of potato moths according to the data of pheromone traps. These data make it possible to simplify the monitoring system for the development of the pest and make optimal decisions in their extermination. The idea of the proposed algorithms is to form a set of preferred features and make diagnostic decisions based on comparing these features.

Keywords: regulation of quantity, pheromone traps, mathematical models, potato moth, monitoring system, diagnostics and forecast
\end{abstract}

\section{Introduction}

In recent years, a significant part of the Uzbekistan's crop in has been damaged by the potato moth (Phthorimaea operculella Zell), which is a quarantine pest for the republic. Potato moth larvae not only damage potatoes in storage areas, but also damage potato plantings during the growing season. This pest can simultaneously damage potatoes and other plants of the nightshade family group (tomato, eggplant, pepper, tobacco, etc.)

An important role in reducing crop losses from potato moths is played by monitoring their numbers and signaling the timing of their control. The currently used methods of monitoring and accounting for the number of potato moths (route surveys of observers from plant protection units, the use of the sums of effective temperatures in determining the timing of the appearance of the pest, light and other types of traps, etc.) are rather laborious $[1,2]$. With the help of these methods, it is not always possible to determine the condition of the pest in large areas and to make optimal decisions on their treatment. The use of pheromone traps in the regulation of the number of potato moths will greatly simplify the monitoring system for the development of the pest and make optimal decisions in the fight against them [2]. In addition, the use of sex pheromones will optimize the timing and amount of use of pest control agents.

Evaluation of the effectiveness of using pheromone traps used to determine the number of potato moths shows that the accuracy of predictions is not always sufficient [2]. This is due to the fact at when determining the number of pests, information on environmental factors is not used sufficiently. In this regard, research on the development of special mathematical models, for example as in [3], allowing to take into account the factors of the abiotic and biotic environment, in order to reduce the risk of the error.

As the experience of modeling such processes shows, the main issues are the selection and minimization of a set of informative indicators of forecasts $[3,4]$.

\section{Research Results}

The effectiveness of methods for predicting increase in numbers of pests depends mainly on the system or recording the initial information and the algorithm for processing it. The system for recording the initial information (in our case, the data of pheromone traps) is a certain technique for retrieving information. The algorithm for processing accounting information includes an algorithm for averaging information (in this case, data from pheromone traps from an accounting site) and a mathematical model tor predicting the number of pests.

Based on this, this article discusses the issues of data accounting when synthesizing algorithms for processing information from pheromone traps.

To develop a mathematical model for predicting the intensity of egg laying in the cotton bollworm, depending on the number of captured 
males, we used the data obtained from pheromone traps of the pest. Pheromone traps were located in the fields 3-5 days before the start of the butterfly departure. We have experimentally found that one trap catches on average $35-40 \%$ of male potato moth butterflies. When determining the intensity of clutches of pest butterflies, such biological indicators as the fertility of one female and the number of eggs in one clutch are taken into account. To calculate the number of clutches of potato moth butterfly eggs $(\mathrm{Kk})$, the following formula can be used:

$$
\mathrm{K}_{\mathrm{k}}=\mathrm{N} / \mathrm{K}_{\mathrm{p}} \quad \mathrm{x} \quad \mathrm{S}
$$

where $\mathrm{N}$ is the number of pest eggs at the registration site; $\mathrm{K}$ - the number of plants; $\mathrm{S}$ - average number of eggs in one clutch.

The predicted number of pest eggs is calculated by the formula:

$\mathrm{N}=1 / 2 \mathrm{~K}_{\mathrm{c}} \times \mathrm{S}_{\mathrm{p}}$

Where $K_{\mathrm{c}}$ is the number of males caught on average per 1 trap; $S_{\mathrm{p}}$ is the average fertility of one female potato moth.

Since the sex ratio of potato moth is $1: 1$, formulas above can determine the expected number of pest eggs in the particular field.
To determine the average fertility of one female potato moth $\left(S_{p}\right)$ on potato crops, a model was developed in the form:

$$
S_{p}=-31.91+16,06 X_{p}+1,10 X_{m}-0,09 X_{p} X_{m} \text {, }
$$

where $X_{m}$ is the mass of pupae; $X_{p}$ is the size of the pupae.

The correlation coefficient is very high, $\mathrm{R}=0.94$; and the approximation error was 14,5 eggs.

Then formula (1) taking into account formula (2) takes the form:

$\mathrm{N}=1 / 2 \mathrm{~K}_{\mathrm{c}}\left(-31,91+16,06 \mathrm{X}_{\mathrm{p}}+1,10 \mathrm{X}_{\mathrm{m}}-0,09 \mathrm{X}_{\mathrm{p}} \mathrm{X}_{\mathrm{m}}\right)$.

The average germination of potato moth butterflies obtained according to the actual and formula 3 is given in the table. Comparison of these values allows us to conclude that using formula (3) it will be possible to determine the average fecundation, knowing the mass and size of the moth pupae. The data obtained have been tested in the practice of plant protection stations in Andijan and Khorezm regions and provide an opportunity to solve such an important problem as the placement, forecasting and control of pheromone traps in potato fields.

\begin{tabular}{|c|c|c|c|c|}
\hline \multirow{2}{*}{ No } & \multicolumn{2}{|c|}{ Fertility (number of eggs), pcs. } & $\begin{array}{c}\text { Mass of pupae } \\
\text { mg }\end{array}$ & $\begin{array}{c}\text { Size of pupae, } \\
\text { mm }\end{array}$ \\
\cline { 2 - 3 } & In fact & calculated & 275 & 17,5 \\
\hline 1 & 785 & 803 & 260 & 17,5 \\
\hline 2 & 622 & 618 & 260 & 16,0 \\
\hline 3 & 300 & 317 & 310 & 19,5 \\
\hline 4 & 1011 & 998 & 296 & 19,0 \\
\hline 5 & 940 & 916 & 280 & 17,5 \\
\hline 6 & 698 & 676 & 285 & 18,0 \\
\hline 7 & 786 & 741 & 280 & 17,5 \\
\hline 8 & 638 & 613 & 265 & 17,0 \\
\hline 9 & 320 & 301 & 310 & 20,0 \\
\hline 10 & 1040 & 983 & 295 & 19,0 \\
\hline 11 & 993 & 975 & 285 & 17,5 \\
\hline 12 & 680 & 636 & 295 & 18,5 \\
\hline 13 & 789 & 796 & 255 & 18,0 \\
\hline 14 & 815 & 841 & 280 & 16,5 \\
\hline 15 & 220 & 280 & 310 & 19,5 \\
\hline 16 & 1090 & 1043 & 310 & 19,5 \\
\hline 17 & 1010 & 1001 & 285 & 17,0 \\
\hline 18 & 625 & 639 & & \\
\hline
\end{tabular}

Table 1. Comparison of the average fecundity of potato moth butterflies depending on the mass and size of pupae.

The issues of creating and using information systems and technologies in agricultural production, in modern conditions, are becoming a fundamental factor in the development of innovation and scientific and technological progress in the industry. One of the main tasks in the field of application of modern information technologies is associated with the creation of computer systems for diagnosing diseases of agricultural crops and predicting the development of this group of diseases. The use of an automated diagnostic system makes it possible to dramatically increase the use of objective diagnostic information and makes it possible for an earlier and more accurate diagnosis of plant diseases and decision -making on plant protection measures. Methods and algorithms for pattern recognition are central to the development of computer systems for the diagnosis of plant diseases.

In practice, applied problems are more common, associated with the recognition of patterns specified in the space of large features (for example, recognition of defects based on flaw detection and metallographic images, recognition of a person from a face image, etc.). One of the applied problems of this kind is the problem of plant diseases diagnostics by the image of their leaves. When solving this problem, the processed information is represented by a numerical matrix [5-7]. In this case, the original image of leaves for diagnosis is redundant, many local characteristics calculated for each fragment of the original image are interconnected. Under these conditions, the construction of a diagnostic algorithm faces great computational difficulties. That is why, the development and modification of algorithms for diagnosing plant diseases based on the image of their leaves are relevant.

Based on this, the article discuses an original approach to the problem of diagnosing the phytosanitary state of cultivated plants. A distinctive feature of the considered approach to solving the diagnostic problem is the formation of preferred diagnostic features set and the construction of algorithms for the transition from separate diagnostic algorithms to a model -a family of algorithms for a unified description of solution methods. It should be noted that this work is a revised and 
supplemented version of work [8], which considers the issues of identifying the features of images of plant leaves in the diagnosis.

The aim of this work is to develop a model of algorithms for diagnosing plant diseases based on the analysis of image of their leaves. The proposed models of algorithms are based on the principle of potentials [5].

To solve this problem, model of modified diagnostic algorithms based on the principle of potentials is proposed. The main idea of the proposed model consists in the formation of a certain set of parameters, which makes it possible to determine the system of preferable diagnostic features based on permissible images of leaves, and to recognize the phytosanitary state by these features. In this case, the spatial (two-dimensional) structure of leaf images is represented as a one- dimensional feature space of high dimension. Each feature characterizes only a certain area (fragment) of the image under consideration. (numerical characteristics)

It should be noted that individual characteristics calculated for all fragments of image are considered as a separate feature space, the algorithms of which were considered in [5].

For practical use and performance assessment of the proposed diagnostic algorithms, functional diagrams and corresponding diagnostic programs have been developed. The developed programs are implemented in the Delphi language. In order to test the efficiency of the developed programs, let us consider the problem of diagnosing the development of a potato moth using images of potato leaves.

It is known that the potato moth is considered the most harmful and dangerous to the potato crops in many parts of the world. The harmfulness of the potato moth and the volume of crop losses caused by them depend on a number of factors, the primary damage (i.e., the phase of development of the potato, the time of the onset of development of the moth), the intensity of development of the pest, and others.

\section{Conclusion}

Diagnostics of the phytosanitary state of agricultural crops and information support for decision-making on their protection is one of the main tasks in the problem of crop management. Despite this, the problems of developing and using automated systems for diagnosing diseases of cultivated plants have not been sufficiently studied.

A model of algorithms for diagnosing diseases of cultivated plants based on images of their leaves has been developed. The main idea of the proposed model of algorithms is to recognize the phytosanitary state of agricultural crops by diagnostic signs. In this case, the formation of diagnostic features is based on the calculation of various statistical characteristics for each fragment of the original image.

In the process of solving a practical problem, it was determined that the stages of forming subsets of «independent» features, namely, the issues of determining the number of these subsets and a set of diagnostic features from the image of leaves, as well as the choice of a recognition model, are of the most importance in solving the diagnostic problem. Therefore, it is necessary to continue research taking into account the identified areas.

The developed model can be used when compiling various software system for solving problems of object classification, given in the form of image.

\section{References}

1. Filippov N.A., Guliy V.V. (1986) Current problems of biological regulation for the number of harmful organisms. In the book: "Biological regulation of the number of harmful organisms". -M.: Agropromizdat. -P. 3-12.

2. Kovalev B.G. (1986) The main results of the study of insect sex pheromones. From the book: "Biological regulation of the number of harmful organisms". -M.: Agropromizdat. -P. 12-25.

3. Yakhyaev Kh.K. (1994) Development of scientific foundations for automation of forecasting and management of harmful object in agricultural crops. -Dissertation. doctors of agricultural sciences. - Tashkent. -286 p.

4. Yakhyaev Kh.K., Kholmuradov E.A. (2005) Automation of forecasting the development and spread of pests and diseases in agricultural crops. -Tashkent: FAAK.-168 p.

5. Zhuravlev Yu.I., Ryazanov V.V., Senko O.V. (2006) Recognition. Mathematical methods. Software system. Practical applications. -M.: Fazis. -159 p.

6. Woods R., Gonzales R. (2005) Digital Image Processing. -M.: Technosphere. $-752 \mathrm{p}$.

7. Mirzaev N.M. (2010) About one model of image recognition. Computer Technology and Applications: Proceedings of The First Russia and Pacific Conference, Vladivostok, Russia. -Pp. 394-398. -access mode ftp://ftp.dvo.ru/pub/RPC 2010/rpc2010_docs/

8. Yakhyaev Kh.K., Fazylov Sh.Kh., Daminov O.A., Mirzaev O.N. (2012) Algorithms for the diagnosis of plant diseases by the image of their leaves. Mat. $5^{\text {th }}$ international conference. Novosibirsk, 2012. -Pt. 1. -Pp. 242-2

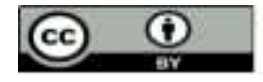

This work is licensed under Creative Commons Attribution 4.0 License

To Submit Your Article Click Here: Submit Manuscript

DOI: $10.31579 / 2766-2314 / 036$
Ready to submit your research? Choose Auctores and benefit from:

*ast, convenient online submission
rigorous peer review by experienced research in your field
rapid publication on acceptance
* authors retain copyrights
* imique DOI for all articles
immediate, unrestricted online access

At Auctores, research is always in progress.

Learn more https://auctoresonline.org/journals/biotechnology-andbioprocessing 